“C 2017 IEEE. Personal use of this material is permitted. Permission from IEEE must be obtained for all other uses, in any current or future media, including reprinting/republishing this material for advertising or promotional purposes, creating new collective works, for resale or redistribution to servers or lists, or reuse of any copyrighted component of this work in other works." 


\section{Hysteresis Band Current Controller based Field- Oriented Control for an Induction Motor driven by a Direct Matrix Converter}

\author{
Jianwei Zhang, Li Li \\ Faculty of Engineering and IT \\ University of Technology Sydney \\ Sydney, Australia \\ Jianwei.Zhang@uts.edu.au,Li.Li@uts.edu.au
}

\author{
Lei Zhang \\ School of Mechanical Engineering \\ Beijing Institute of Technology \\ Beijing, China \\ Lei_zhang@bit.edu.cn
}

\author{
David G. Dorrell \\ Howard College Campus \\ University of KwaZulu-Natal \\ Durban, South Africa \\ Dorrelld@ukzn.ac.za
}

\begin{abstract}
This paper presents work on the hysteresis band control for output current regulation in a direct matrix converter in order to drive an induction motor. The hysteresis band controller offers excellent dynamic performance. It has been extensively researched for the voltage source inverter and inverter based drive systems, but it has not been investigated within the context of a matrix converter or a matrix converter based motor drive. Firstly, this paper proposes a fixed-band hysteresis current controller for a matrix converter to track the prescribed current references, and then a sinusoidal-band hysteresis current controller is proposed. Both methods have fast dynamic performance and they inherently integrate the line modulation technique of the virtual rectifier stage into the overall modulation. The extra modulation stage is not required and the surge current is inherently prevented. The sinusoidal-band hysteresis controller demonstrates that it generates lower harmonic content at the expense of the higher average switching frequency. Following this, both methods are tested as a drive for an induction motor with field-oriented control. With the matrixconverter-based drive system, one significant benefit is that the braking chopper is removed due to the bidirectional feature. The methods are simple and have light computation burden. The obtained results demonstrate the effectiveness and feasibility of the proposed scheme. The experimental work is being carried out to support the proposed scheme.
\end{abstract}

Keywords-Matrix Converter; Hysteresis Band; Current Controller; AC Motor Drive; Electric Vehicle

\section{INTRODUCTION}

Field-oriented control (FOC) is the most commonly employed linear strategy for medium- and low-power motor drives [1]. Nowadays, FOC-based electrical drive systems are mature and used extensively in high-performance drives [2]. Current controllers are vital components in the FOC method. Meanwhile, electrical drive systems composed of an induction motor (IM) and a voltage source inverter (VSI) are popular in adjustable speed drives in industry and transport [3]. For the VSI based drive system, current controllers are preferred for the high-performance drives because of their excellent dynamic behavior. Among these current controllers, the hysteresis band (HB) current controller features inherent current limiting capability, robustness, no modulation stage, and simple implementation, in addition to the excellent dynamic performance. The HB control has been constrained to the VSI and active research on this includes constant switching frequency control [4], online computation of bands [5], and multi-band hysteresis control [6]. For a high inertia system that requires dynamic braking, the VSI based drive system usually requires a rectifier stage to supply the DC voltage and the braking chopper to absorb the kinetic energy generated from the motor deceleration as shown in Fig. 2. These will make the system bulkier, decrease efficiency and increase the complexity.

These problems can be addressed with the matrix converter based drive system adopting abovementioned control techniques. A $3 \times 3$ direct matrix converter $(\mathrm{MC})$, as shown in Fig. 1, is a flexible power converter which is capable of bidirectional power flow, sinusoidal waveform, regenerative ability, controllable input power factor and compact volume [7]. Besides motor drive applications, matrix converter and its derivatives have been proposed for numerous applications including aerospace systems [8], microgrids [9], FACTS [10] and electric vehicles [11].

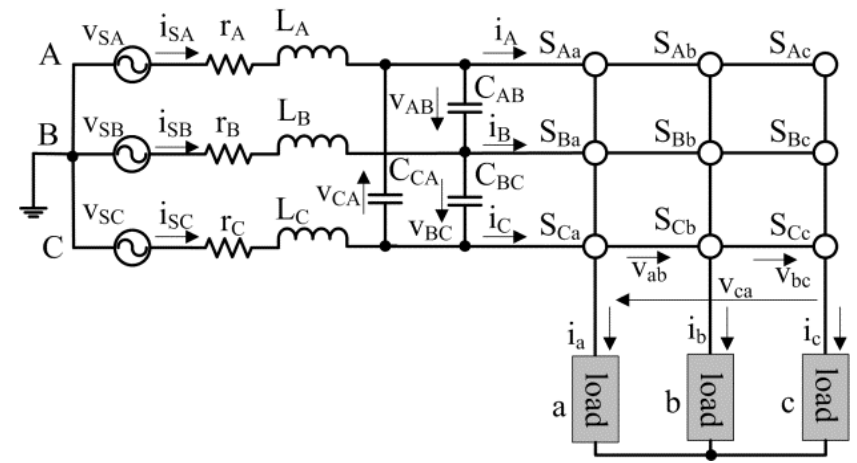

Fig. 1. A three-phase direct matrix converter system with input filters

A $3 \times 3$ direct matrix converter provides direct $\mathrm{AC}$ to $\mathrm{AC}$ power conversion with bidirectional power flow capability; therefore, the rectifier stage and the braking chopper are not required in the $\mathrm{MC}$ based drive system and this also enables the four-quadrant operation. Direct torque control (DTC) and predictive torque control (PTC) have been researched for the MC based drive system [12]-[16]. In the case of the matrix converter, the computing burden of the predictive control is heavy because of the high number of switch actions (27 possibilities) and the limited speed of the microprocessor.

This work is supported in part by the China Scholarship Council (File No. 201406300161) 


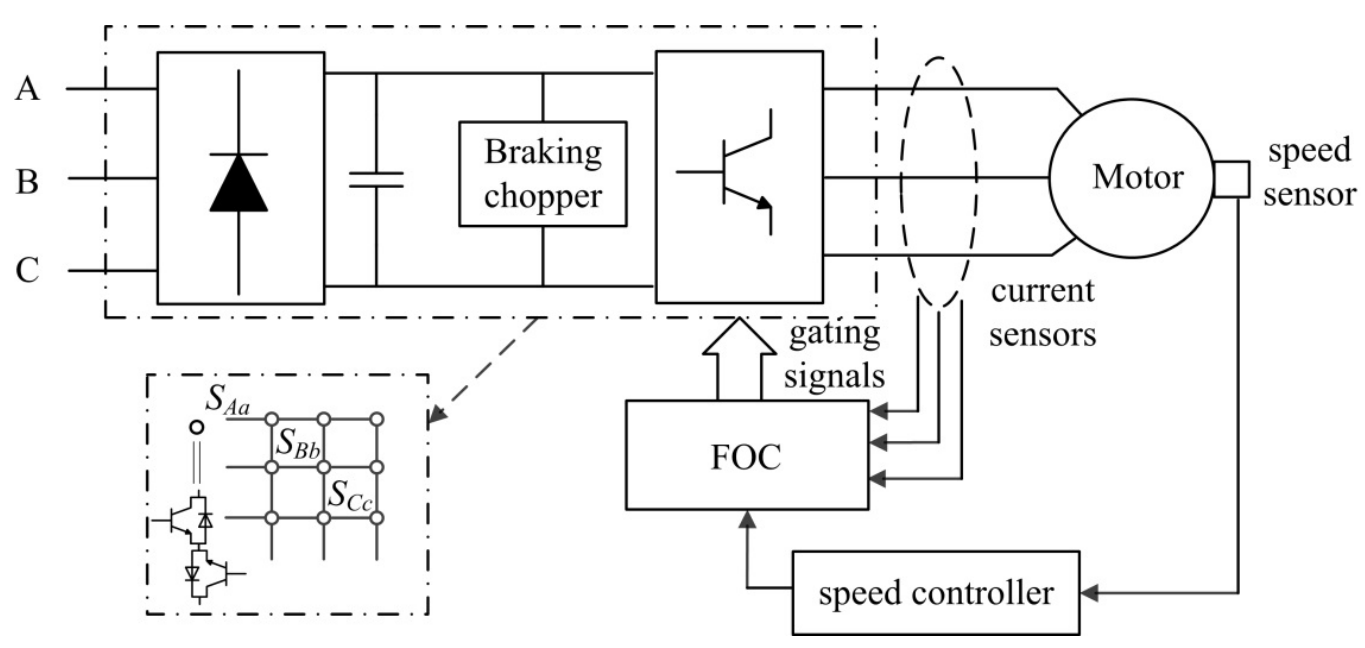

Fig. 2. The FOC based drive system with VSI or MC

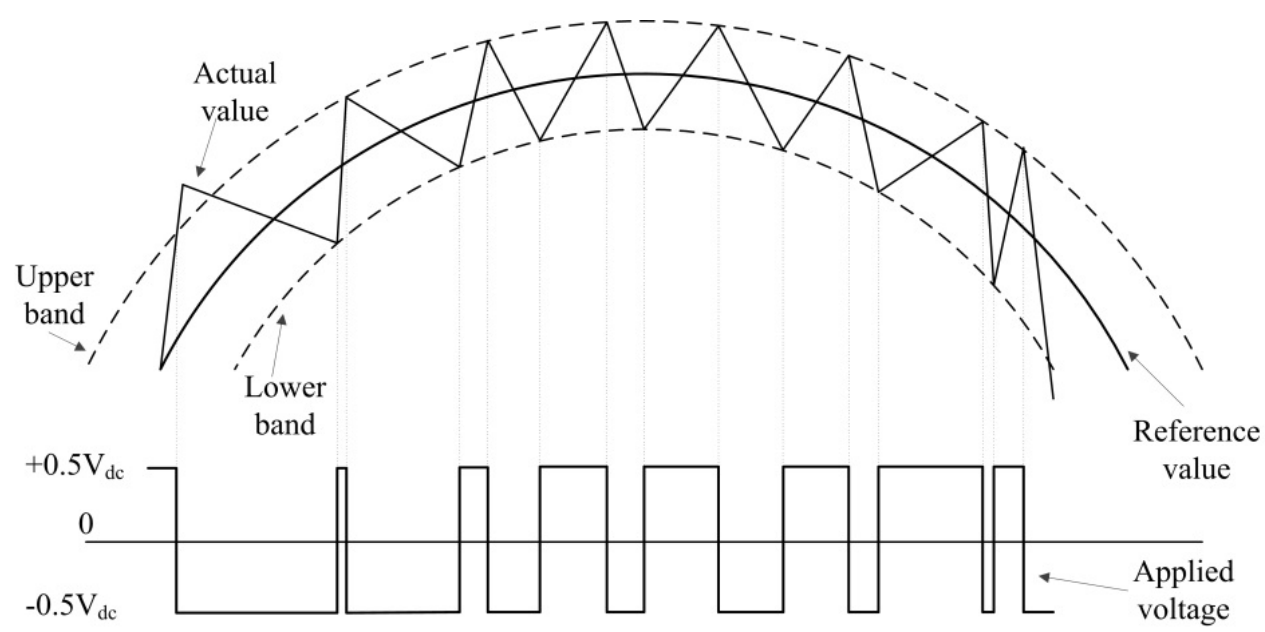

Fig. 3. The HB current control illustration for the 2-level VSI

Therefore, predictive control might not be very practical for a MC-based drive system. The HB controller is simple and the computing burden (execution time) is light. However, HB and HB-based FOC have not been examined for a $3 \times 3 \mathrm{MC}$ or MC-based drive systems.

This work proposes and studies the HB current controller and HB based FOC for an IM drive. The controller does not require an extra modulation stage but inherently includes the modulation of the virtual rectifier stage. Both the fixed-band (F-HB) and sinusoidal-band (S-HB) HB current controllers are developed and compared for the MC. Both methods demonstrate good dynamic features. Comparative results show that the S-HB controller has less low-order harmonics and THD at the cost of the higher average switching frequency. Next, the HB current controllers are integrated with the FOC to drive an IM with an MC. S-HB shows lower stator and torque ripple. The braking chopper is not required in this structure. These are the objectives and contributions of this paper.

\section{HB CONTROLLER FOR THE MC OUTPUT CURRENT}

\section{A. Fixed-band hysteresis control for $M C$}

The HB current controller for the VSI is described by (1) and (2) and shown in Fig. 3. Here $h$ is the HB width. The control law (2) is straightforward. When the actual current exceeds the upper band, the upper/lower leg is turned off/on to reduce the current and vice versa. Therefore, the actual currents will always be regulated to stay within the prescribed boundaries in theory. Similarly the HB current controllers for an $\mathrm{MC}$ can be developed.

$$
\begin{aligned}
& h_{\text {upper }}=I_{\text {ref }} \sin \left(\omega_{\text {ref }} t+\theta_{\text {ref }}\right)+\frac{h}{2}, \\
& h_{\text {lower }}=I_{\text {ref }} \sin \left(\omega_{r e f} t+\theta_{\text {ref }}\right)-\frac{h}{2} .
\end{aligned}
$$

If $I_{a}>I_{\text {upper }}, V_{a o}=-0.5 V_{d c} ; \quad$ If $I_{a}<I_{\text {lower }}, V_{a o}=+0.5 V_{d c}$. 


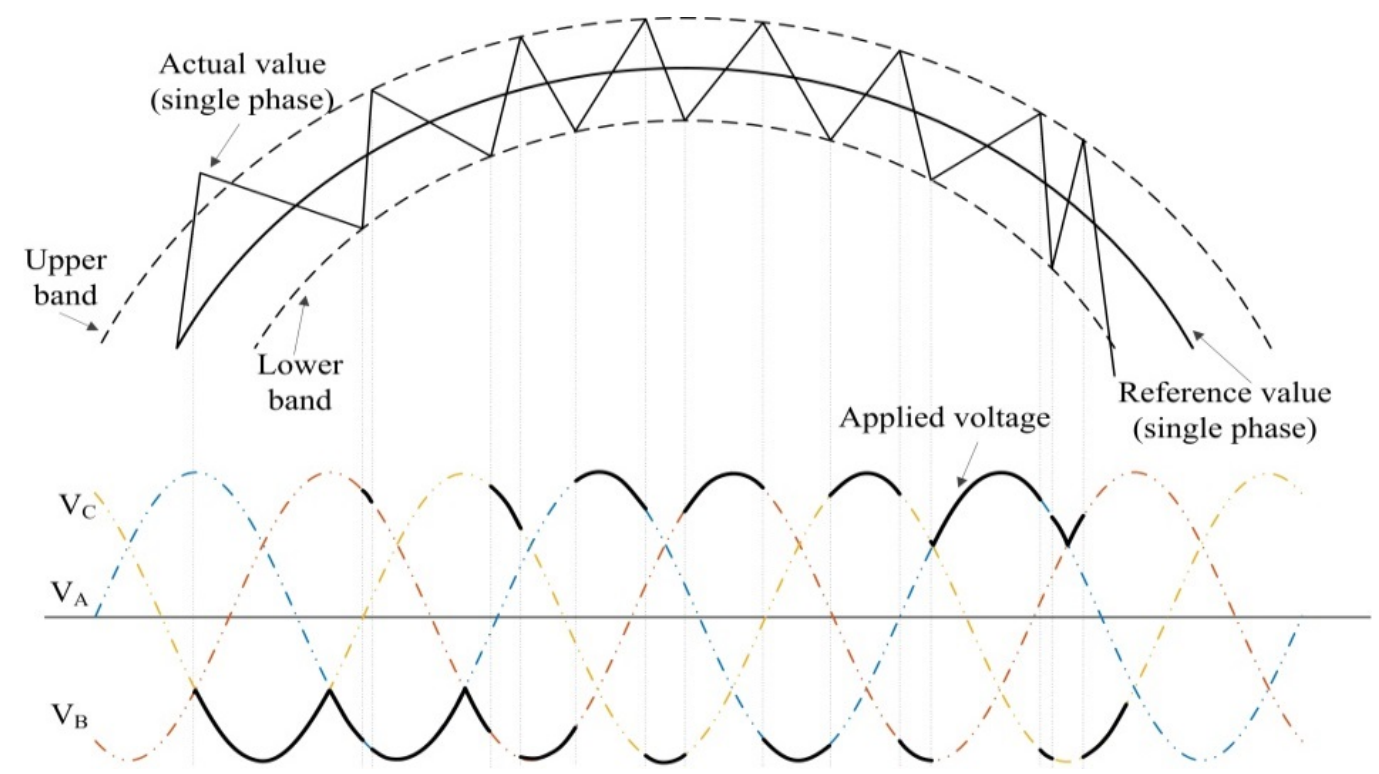

Fig. 4. The FOC based drive system with VSI or MC

$$
\begin{aligned}
& \text { If } I>I_{\text {upper }}, V_{a}=\operatorname{minimum}\left(V_{A}, V_{B}, V_{C}\right) \text {; } \\
& \text { if } I<I_{\text {lower }}, V_{a}=\operatorname{maximum}\left(V_{A}, V_{B}, V_{C}\right) \text {. }
\end{aligned}
$$

In terms of the $\mathrm{MC}$, the upper and lower bands (1) for the F- HB are shown in Fig. 5(a) for a single phase. The controller law is similar to the VSI. In Fig. 4 a single phase current control is depicted and the maximum or minimum voltages are selected to increase or decrease the currents as shown in (3). It is worth noting that the MC offers more flexibility compared with VSI as it offers more voltage choices including zero states. The zero states can also be utilized to reduce the switching frequency based on the fact that the three-phase current cannot reach upper or lower bands at the same time. Therefore, the balance among three-phase currents can be made use of to regulate the currents and to reduce switching actions.

\section{B. Sinusoidal-band hysteresis control for $M C$}

The sinusoidal bands (4) are shown in Fig. 5(b). With the $\mathrm{S}-\mathrm{HB}$, the control law is slightly modified as the upper and lower bands are alternated every half cycle. If the reference current is in the positive half cycle and when the actual current exceeds the upper band, the voltage which enables current reduction is selected; when the actual current reaches the lower band, the voltage which drives current increase is selected; see (5). Alternatively, if the reference current is in the negative half cycle and when the actual current exceeds the upper band, the maximum voltage which is able to increase the current is employed; when the actual current reaches the lower band, the minimum voltage which can decrease the current is employed; see (6). Therefore, the actual currents can be theoretically controlled to be within the predefined band-width regions.

$$
\begin{aligned}
& h_{\text {upper }}=\left(\mathrm{I}_{r e f}+\frac{h}{2}\right) \sin \left(\omega_{\text {ref }} t+\theta_{\text {ref }}\right), \\
& h_{\text {lower }}=\left(\mathrm{I}_{r e f}-\frac{h}{2}\right) \sin \left(\omega_{r e f} t+\theta_{\text {ref }}\right) .
\end{aligned}
$$

For $I_{\text {ref }}>0, \quad$ if $I>I_{\text {upper }}, V=\operatorname{minimum}\left(V_{A}, V_{B}, V_{C}\right)$;

$$
\text { if } I<I_{\text {lower }}, V=\operatorname{maximum}\left(V_{A}, V_{B}, V_{C}\right) \text {. }
$$

For $I_{r e f}<0, \quad$ if $I<I_{\text {upper }}, V=$ maximum $\left(V_{A}, V_{B}, V_{C}\right)$;

$$
\text { if } I>I_{\text {lower }}, V=\operatorname{minimum}\left(V_{A}, V_{B}, V_{C}\right) \text {. }
$$

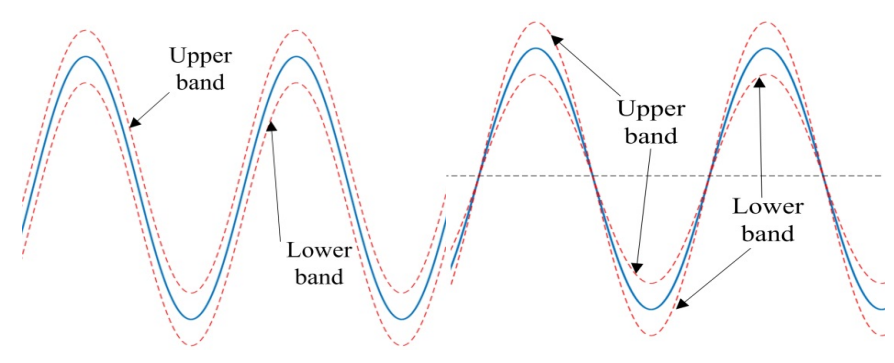

(a)

(b)

Fig. 5. Diagram of the HB band (a) F-HB, (b) S-HB

\section{OVERALl MODULATION OF MATRIX CONVERTER}

The above methods inherently integrate the linecommutated modulation of the MC input currents. To explain this, the MC modulation is divided into a virtual rectifier and a virtual inverter stage as shown in Fig. 6. These two virtual stages can be modulated independently using different methods. The output current modulation is based on the virtual inverter stage as VSI HB control, while the input current modulation is based on the virtual rectifier stage. For example, 
in F-HB, if the output phase $a$ current $I_{\mathrm{a}}$ reaches the lower band $\left(I_{\mathrm{a}}<h_{\text {lower }}\right)$ and the maximum input voltage is $V_{B}$ at this moment, then $S_{P a}$ and $S_{P B}$ in Fig. 6 are turned on to increase the currents. Thus, the output phase $a$ is connected to the input phase $B$. Therefore, the equivalent switch $S_{B a}$ in Fig. 1 is switched on. The same rule applies to other situations. As a result, the input currents are controlled automatically. An equivalent look-up table can be tabulated based on this. It is worth noting that different modulation techniques such as SVM for the virtual rectifier stage can be incorporated into the overall modulation scheme to control the input currents in an expected way.

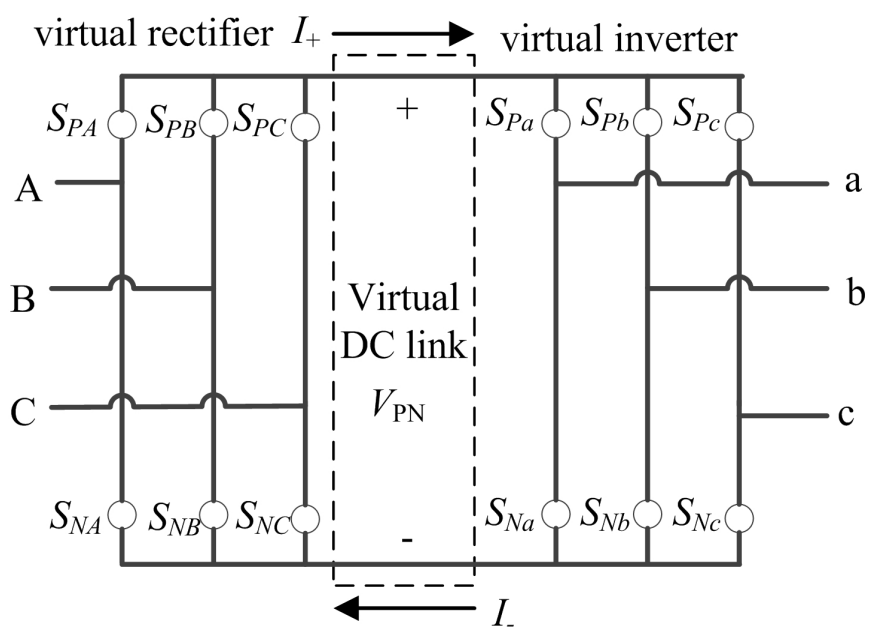

Fig. 6. The equivalent virtual rectifier and inverter stage for the overall modulation explanation

\section{HB CURRENT CONTROL FOR MC-IM DRIVE}

\section{A. Model Description}

In this section, the FOC control is implemented for the $\mathrm{MC}$ based drive system using the HB current controller. The FOC converts the IM dynamics so they are similar to an equivalent DC motor where the torque and flux are decoupled. FOC relies upon the fact that the motor rotor flux and torque can be controlled through the $\mathrm{d}$ and q components of the stator current which are usually provided by the current controlled PWM inverter. Based on the IM model and a rotating reference frame, the equations obtained for the FOC control are expressed in (7) to (11) [17].

$$
\begin{gathered}
i_{d s}^{*}=\frac{\left|\psi_{r}\right|^{*}}{L_{m}} \text { (7), } \quad i_{q s}^{*}=\frac{2}{3} \cdot \frac{1}{p} \cdot \frac{L_{r}}{L_{m}} \cdot \frac{T_{e}^{*}}{\left|\psi_{r}\right|_{e s t}} \\
\left|\psi_{r}\right|_{e s t}=\frac{L_{m} \cdot i_{d s}}{1+T_{r} \cdot s} \quad(9), \quad \theta_{e}=\int\left(\omega_{m}+\omega_{s l}\right) d t \\
\omega_{s l}=\frac{L_{m}}{\left|\psi_{r}\right|_{e s t}} \cdot \frac{i_{q s}}{T_{r}}
\end{gathered}
$$

where $L_{r}$ is the rotor inductance, $p$ is the number of pole pairs, $L_{m}$ is the mutual inductance, $\left|\psi_{r}\right|_{e s t}$ is the estimated rotor flux, $T_{r}=L_{r} / R_{r}$ is the rotor time constant, $\omega_{m}$ is the rotor speed and $\omega_{s l}$ is the slip frequency (angular velocity). The $\mathrm{d}$ component of stator current $i_{d s}$ can be derived from the rotor flux reference using (7). In order to carry out the coordinate transformation $(a b c \leftrightarrow d q)$, the rotor flux position $\theta_{e}$ is required and it can be calculated from (10) and (11). The torque reference $T_{e}{ }^{*}$ can be either specified by the operator or obtained using a speed regulator. Here a PI controller is used to generate the torque reference from the speed error. The obtained $i_{d s}$ and $i_{q s}$ references are converted to the $a b c$ frame and then sent to the MC $\mathrm{HB}$ controller.

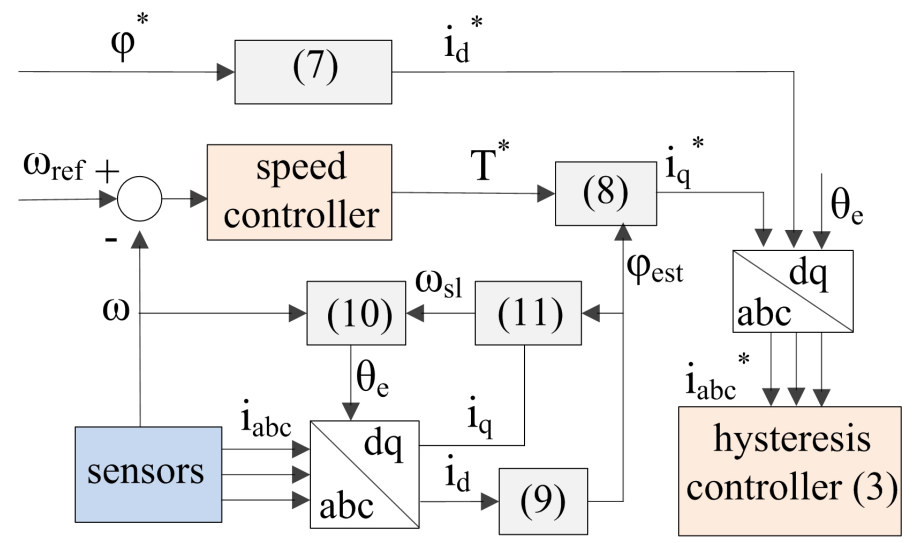

Fig. 7. HB-FOC controller diagram for the MC based drive system

\section{B. HB-FOC Controller Design}

Based on the model derived above, the FOC controller combined with the HB controller can be designed as shown in Fig. 7. The HB controller generates gating signals for the semiconductor devices, and sensors are used to measure the motor speed and currents. The speed controller adopted in this work is a PI controller whose parameters are given in Table I.

\section{Simulation Results}

The simulated system and controller parameters are tabulated in Table 1. Simulation results are shown in Figs. 8 11 for the F-HB and S-HB controllers. The dynamic response of the F-HB and S-HB controllers are shown in Fig 8. The current reference is $I_{r e f}=2.5 \sin (200 \pi \mathrm{t})$ A before $0.025 \mathrm{~s}$ and doubled after this point of time. According to the simulation results shown in Figs. 8(a-b), it is convincing to say that both methods present excellent dynamic performance. The actual stator currents are practically confined within the prescribed bands. According to the FFT analysis shown in Figs. 10(a-b), the S-HB method has lower harmonic distortion (low-order harmonics in particular) and causes higher average switching frequency as described in Figs. 9(a-b). The THD of current is reduced from $3.95 \%$ to $2.87 \%$. Although the average switching frequencies are increased, they are around $10 \mathrm{kHz}$ which are reasonably acceptable for current semiconductor switches.

Table 1 Simulation system and controller parameters for F/S-HB based MC drive

\begin{tabular}{ccccccccccccc}
\hline$R_{S}(\Omega)$ & $R_{r}(\Omega)$ & $L_{s}(\mathrm{H})$ & $L_{r}(\mathrm{H})$ & $L_{m}(\mathrm{H})$ & $p$ & $J\left(\mathrm{~kg} \cdot \mathrm{m}^{2}\right)$ & $\varphi_{s N}(\mathrm{~Wb})$ & $T_{N}(\mathrm{~N} \cdot \mathrm{m})$ & $k_{p}$ & $k_{i}$ & $h$ & $T_{s}(\mathrm{~s})$ \\
\hline 3.126 & 1.879 & 0.230 & 0.230 & 0.221 & 2 & 0.1 & 0.9876 & 14 & 30 & 5 & 0.1 & $1 \times 10^{-5}$ \\
\hline
\end{tabular}




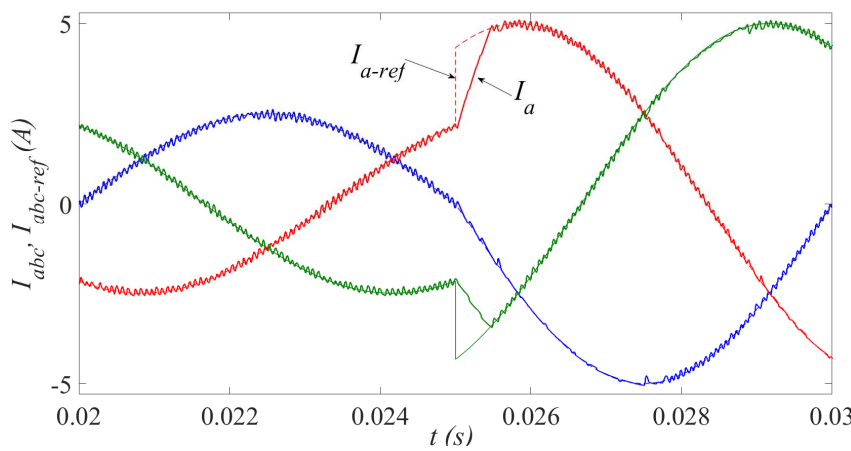

(a)

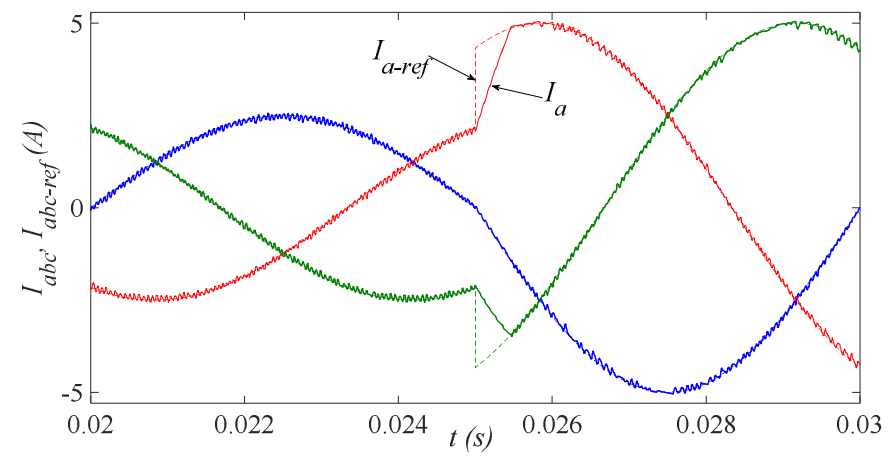

(b)

Fig. 8. Simulation results of (a) F-HB and (b) S-HB dynamic performance

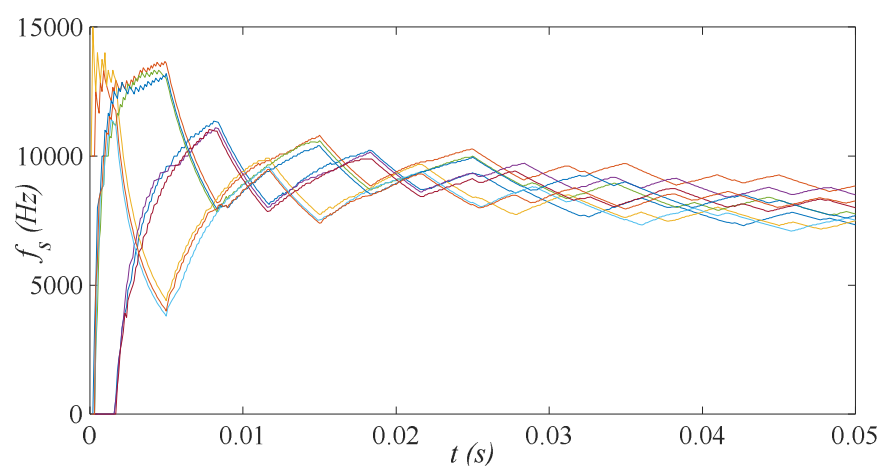

(a)

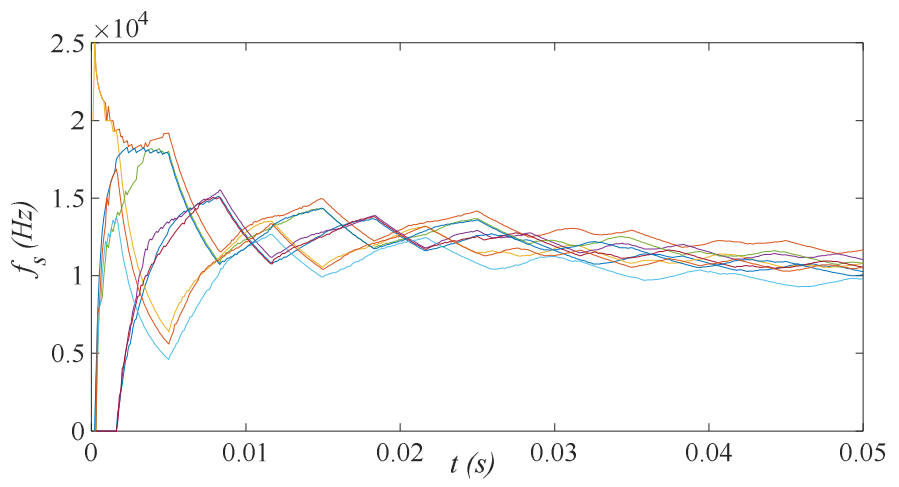

(b)

Fig. 9. Simulation results of (a) F-HB and (b) S-HB average switching frequency

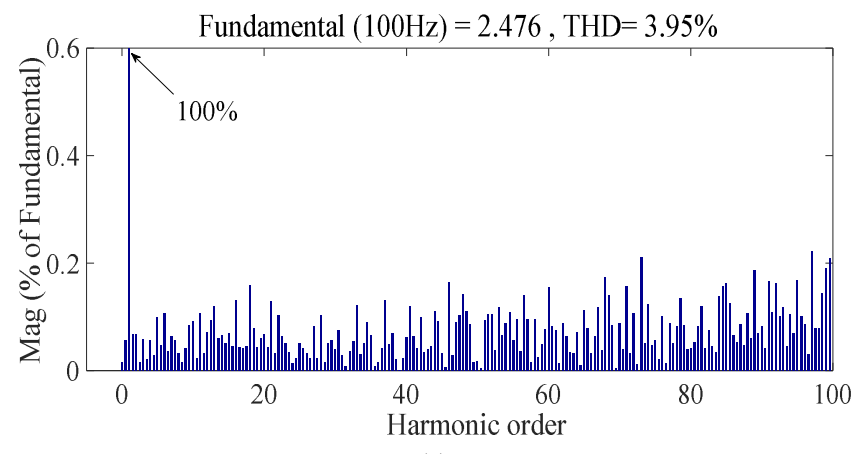

(a)

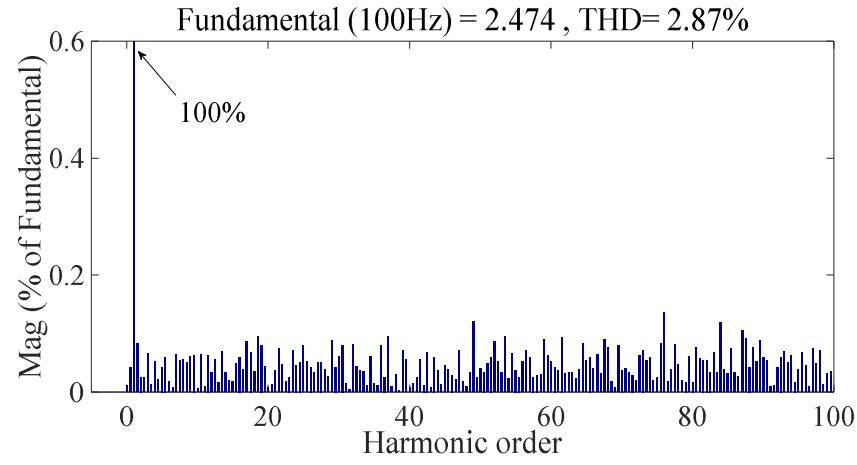

(b)

Fig. 10. Simulation results of (a) F-HB and S-HB FFT analysis
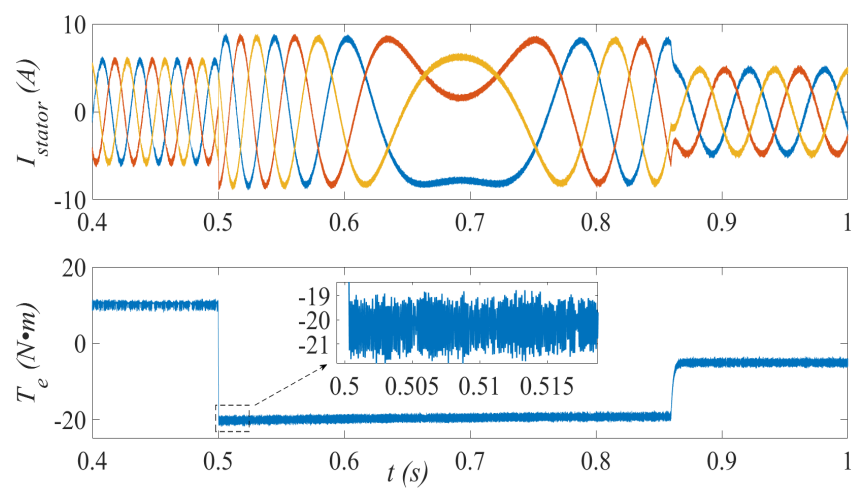

(a)
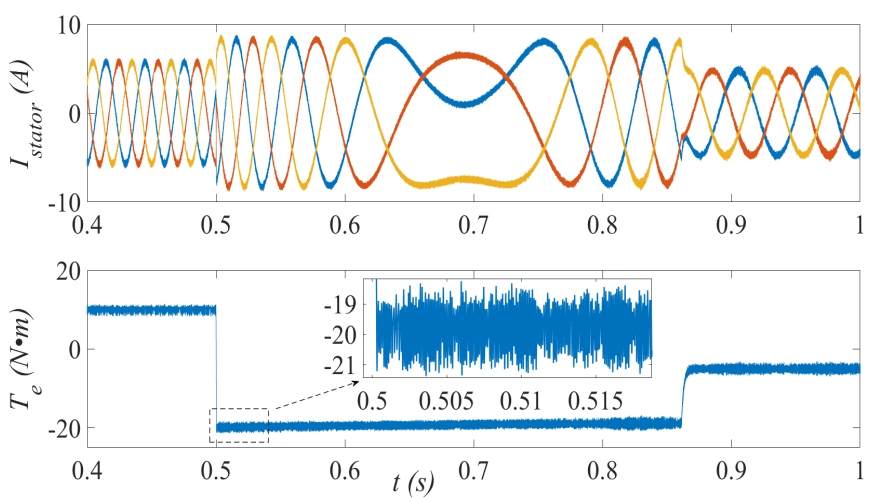

(b)

Fig. 11. Simulation results of HB-FOC based MC drive system in response to the speed change from +100 to $-50 \mathrm{rad} / \mathrm{s}$ at $0.5 \mathrm{~s}$ (a) F-HB and (b) S-HB 
Simulation results for F/S-HB-FOC based MC drives system are shown in Fig. 11. Both methods perform similarly in terms of driving an IM. From the simulation results shown in Fig. 11, the S-HB controller exhibits lower torque ripple and lower harmonic distortion. The motor deceleration and MC regenerative capability are tested under the speed step change from $+100 \mathrm{rad} / \mathrm{s}$ to $-50 \mathrm{rad} / \mathrm{s}$ at $0.5 \mathrm{~s}$. An additional dynamic braking system is not required with this scheme since it is integrated into the $\mathrm{MC}$ drive.

\section{CONCLUSIONS}

The hysteresis band controller based on FOC is popular in VSIs and motor drives based on VSIs; however, it has not been reported in the literature for a direct $3 \times 3$ matrix converter or matrix converter based drive system. This paper introduces the $\mathrm{HB}$ current controller to the $\mathrm{MC}$ and $\mathrm{MC}$ based $\mathrm{AC}$ drive system. This method is simple and the computation burden is appreciably light. Both fixed and sinusoidal band $\mathrm{HB}$ controllers are developed involving the inherent modulation of the input currents, and simulation results are evaluated comparatively. S-HB has better harmonic performance and higher average switching frequency. Depending on the requirements of the application, the specific method can be selected. The input current regulation of the MC is not an objective of this work, so it is not effectively regulated with line-commutation. In order to obtain good results for the input currents, other methods such as SVM can be employed in the overall modulation. It is important to state that this scheme cannot only be applied to the induction motor but also can be applied to other machines such as permanent magnet synchronous machine. The proposed scheme is explicit and effective. A matrix converter based drive system has been developed to verify the results.

\section{REFERENCES}

[1] J. Rodriguez, R. M. Kennel, J. R. Espinoza, M. Trincado, C. A. Silva, C. A. Rojas, "High-performance control strategies for electrical drives: An experimental assessment," IEEE Trans. Ind. Electron., vol. 59, no. 2, pp. 812-820, 2012.

[2] A. Raisemche, M. Boukhnifer, C. Larouci, D. Diallo, "Two active faulttolerant control schemes of induction-motor drive in EV or HEV," IEEE Trans. Veh. Technol., vol. 63, no. 1, pp. 19-29, 2014.

[3] J. Guzinski, H. Abu-Rub, "Speed sensorless induction motor drive with predictive current controller," IEEE Trans. Ind. Electron. vol. 60, no. 2, pp. 699-709, 2013.

[4] J. Peter, G. D. Marques, R. Ramchand, "Current error space vector based constant switching frequency hysteresis controller for VSI fed Induction Motor drives." 9th Int. Conf. Compatibility and Power Electron., pp. 246-251, 2015.

[5] R. Ramchand, K. Gopakumar, C. Patel, K. Sivakumar, A. Das, H. AbuRub, "Online computation of hysteresis boundary for constant switching frequency current-error space-vector-based hysteresis controller for VSIfed IM drives," IEEE Trans. Power Electron., vol 27, no. 3, pp. 1521$1529,2012$.

[6] F. Wu, F. Feng, L. Luo, J. Duan, L. Sun, "Sampling period online adjusting-based hysteresis current control without band with constant switching frequency," IEEE Trans. Ind. Electron., vol. 62, no. 1, pp. 270-277, 2015.

[7] P. W. Wheeler, J. Rodriguez, J. C. Clare, L. Empringham, A. Weinstein, "Matrix converters: a technology review," IEEE Trans. Ind. Electron., vol. 49, no. 2, pp. 276-288, 2002.
[8] S.F. Pinto, P. V. Mendes and J. Fernando Silva, "Modular matrix converter based solid state transformer for smart grids," Electric Power Syst. Research, vol. 136, pp. 189-200, 2016.

[9] J. Zhang, L. Li, Z. Malekjamshidi, D. G. Dorrell, "Predictive Voltage Control of Direct Matrix Converter with Reduced Number of Sensors for the Renewable Energy and Microgrid Applications," 2017 IEEE Energy Conversion Congress and Exposition (ECCE). Unpublished.

[10] J. Zhang, D. G. Dorrell and L. Li, "Applications of the Direct Space Vector Modulation Controlled Matrix Converter as the Unified Power Flow Controller," 8th IET International Conference on Power Electronics, Machines and Drives (PEMD 2016), Glasgow, UK, 2016.

[11] Y. Bak, E.1 Lee, and K. B. Lee, "Indirect matrix converter for hybrid electric vehicle application with three-phase and single-phase outputs," Energies, vol. 8, no. 5, pp. 3849-3866, 2015.

[12] D. Casadei, G. Serra, A. Tani, "The use of matrix converters in direct torque control of induction machines," IEEE Trans. Ind. Electron., vol. 48, no. 6, pp. 1057-1064, 2001.

[13] C. Xia, J. Zhao, Y. Yan, T. Shi, "A novel direct torque control of matrix converter-fed PMSM drives using duty cycle control for torque ripple reduction," IEEE Trans. Ind. Electron., vol. 61, no. 6, pp. 2700-2713, 2014.

[14] R. Vargas, U. Ammann, B. Hudoffsky, J. Rodriguez, P. Wheeler, "Predictive torque control of an induction machine fed by a matrix converter with reactive input power control," IEEE Trans. Power Electron., vol. 25, no. 6, pp. 1426-1438, 2010.

[15] C. Ortega, A. Arias, C. Caruana, J. Balcells, G. M. Asher, "Improved waveform quality in the direct torque control of matrix-converter-fed PMSM drives," IEEE Trans. Ind. Electron., vol. 57, no. 6, pp. 21012110, 2010

[16] K. B. Lee, F. Blaabjerg, "Sensorless DTC-SVM for induction motor driven by a matrix converter using a parameter estimation strategy," IEEE Trans. Ind. Electron., vol. 55, no. 2, pp. 512-521, 2008.

[17] H. Abu-Rub, A. Iqbal, J. Guzinski, High performance control of AC drives with MATLAB/Simulink models. John Wiley \& Sons, 2012. 